\title{
Does Resource Richness, and Good Governance Institution Are Grace for Human Capital Development in Sub- Saharan African Countries?
}

\author{
Ferede Mengistie \\ College of Business and Economics, Department of Economics, Debere Tabor university Ethiopia
}

\begin{abstract}
Human capital development is acquiring of individuals competence via schooling and incentive-based training. To conduct this study panel data type from 2005-2018 and analysis dynamic panel model has been used. The study authenticated the grace of good institution and disgrace resource on human capital. The study verifying that good governance institution attributed by exercising power based on the principles and meritocracy is gracing human capital. But resource richness is not a guarantee to enhance human capital rather it is a means to ineptitude. Given that the researcher recommended as, a responsible bodies in sub-Saharan African countries should be sound institution that enhance good governance via formulate good governance principles, and develop resource merit institution in the favor of human capital development.
\end{abstract}

Keywords:Human capital, governance, Resource, System GMM and sub-Saharan African countries.

DOI: $10.7176 / \mathrm{DCS} / 12-1-02$

Publication date: January $31^{\text {st }} 2022$

\section{INTRODUCTION}

Resource abundances are a means for human capital development. The natural resource is abased for progressive economic, human, and social capital development. In fact, abundant natural resources are imperative apparatus for the development of countries' infrastructure and wealth accumulation. However, natural resource endowment is not enough to accelerate human capital accumulation perhaps it has a crowding-out effect on human capital and preface of public education investment through amplifying the level of resource dependency and increase lessskilled occupations within the human capital development process[1]. Examining the associations between natural resource reliance, public education investment, and human capital accumulation is a critical issue. It deal with why the "blessing" of profuse natural resources frequently turns into a "curse" in several countries and regions, spotlighting on the crowding-out effect of natural resources on human capital. Results of this study redirect the indirect relation between resource abundance and human capital. But, spill-over effects of resource outcome on human capital investment strictly offset expansion of public education investment [2]. In line with this result, the effect of resource endowment negatively affected human capital investment of sub-Saharan African countries through aggravated the dependency of societies instead of looking new opportunities of acceleration human capital development. The effect of natural resources on Economic growth in general and on human capital development in particular is indirect across countries. This is due to institutional dilemmas which manifested by Dutch disease, rent-seeking, and neglect of education investment. In addition to this, resource endowment has a crowed-out effect on Public education investment than national income. Human capital represented by public investment which consisted a set of skills, knowledge, capabilities and attributes personified in people, is decisive to firms' capacity to take up and systematize knowledge and to innovate. [3]

Africa is considered as the slightest developed continent both in economic development and human capital development. Obviously, the inter-linkage among variables like aggregate growth, health, and education indicators is regarded as an imperative driving effort on uplifting human capital development. Explicitly, the development of infrastructure and institutions are also taken as potential drivers of human capital development. Therefore, African governments ought to be enhanced institutional value and infrastructure development to sustained investment in education and health sectors[4].

Governance has been defined in different imperative Contexts. Basically, it refers to how power is exercised on the country's economic, social, and political institution strategies in order to realize resource mobilization and socioeconomic development. Furthermore, Governance involves different affairs that comprised creating conducive political, legal, economic, and human capital. Corruption has negative effect on the economic, social, and political development of countries and which manifested by amplified transaction costs, the diminution in the efficiency of public services, and the discouragement of social values[5]. On the other hand, Corruption is one indicator of bad governance but its effect depends on forms of institution. When the form of an institution is defective corruption is painstaking as "grease the wheels" for boosting economic growth, but for countries that have effective institution corruption is straightly affect economic growth adversely[6]. The outcomes demonstrate that the estimated coefficients for primary and secondary school enrolment and average years of schooling employed as measures of education have a constructive and statistically noteworthy effect on economic growth in 
SSA. Dissimilarity, the approximation for both tertiary school enrolment and government expenditure on education are not statistically important. Furthermore, the calculated coefficients of health confirm a positive and statistically significant effect on economic growth. While making a comparison on the anticipated human capital rate of change on economic growth through two forms indicates the large contribution to escalate level of economic change[7]. As different scholars suggested, resource endowment is a critical point in the process of human capital development, but the in real scenario the continent Africa is really endowed with natural resource whereas the level of human capital is extremely low. Therefore, to examine the effects of resource and governance institution on human capital the study has been conducted.

\section{Literature}

The concept of Human capital in general prescribed as set of individuals' which are attributed by skilled and fashionable use at the labor market. It is also an evident paradox which conferred on recognition of individual's knowledge, competencies, skills, acquisition, maintenance and upgrading. Solely, in economic terms it can be defined as individual's acquisition of knowledge related to the pedagogical, sociological and psychological fields. It is, however, compulsory in order to distinguish between diverse sets of perspectives and objectives. This can typify with the peculiarity between general and occupational education[8].

Good governance refers to the management of government in a move that is fundamentally liberated of abuse and corruption in line with rule of law and respect of people's rights to be engaged in public affairs. Good governance is about strapping the active involvement of communities in decision-making processes and it emphasizes effective collaboration among civil society, governments, and communities. Transparent, inclusive, and effective local development should be ensured by enhancing the capacities of local authorities as conscientious entities towards their communities. To be societies a pillar for good governance, and to develop a sense of good governance institution, mounting awareness and education levels among young people are the most productive strategies[9]. Resource booms may condense human capital accumulation. These booms can swell the opportunity costs of education by favoring low-skill jobs, which makes it optimal for individuals to disrupt their education, this can be decreased college completion, increased low-skill occupations, and had no long-term effects on wealth accumulation[10]

According to the study conducted by [11] important governance indicators that affect human development, results insight that Government Effectiveness, Political Stability, Control of Corruption and Regulatory Quality has a significant effect on human development. It is renowned that government Effectiveness, Control of Corruption, Political Stability and Regulatory Quality are playing a vital role in human development. . The country that will focus on these governance indicators will advance human development and in turns, these improve the well beings of its people. Another study conducted by [12] on government expenditure and corruption: an Indonesian experience by using secondary data and Appling descriptive study, results show that corruption reduces the actual government budget that is intended for human development. Consequently, Human capital nothing contributes to achieve economic growth at expected and potential level. In the other view, corruption is important for economic growth and human capital development of Asian pacific countries which characterized by defective governance institution and it became adverse effect of them when the governance institutions are effective[13].

In addition to this, [14] studied on a blessing or a curse? The long-term effect of resource booms on human capital in Ecuador by using panel data with application of the fixed-effect model show that Resource booms may shrink human capital accumulation. These explosions can amplify the opportunity costs of education by favoring low-skill jobs, which makes it ideal for people to interrupt their education and its disclosure to the boom decreased college completion, increased low-skill occupations finally there will be a weak wealth accumulation.

\section{METHODOLOGY}

To investigate the effect of governance foreign direct investment and natural resource endowment on human capital development in case of Sun-Saharan African countries in 2019/20 the researcher has been used panel data type from 2005-2018. The reliable data obtained from Penn world data source (PWt, 2019), world development indicator (WDI, 2019) worldwide governance indicator data source (WGI, 2019). To analysis Both descriptive and econometric data analysis have carried out and interprets by using the result of system GMM dynamic panel data model with application of stata13 software packages because generalized method of moments (GMM) help to achieve unbiased, consistent, and efficient parameter estimates that best represent the dynamic nature of the model with the set of optimal instrumental variable[15]. Also, GMM brings and helps to ensure consistency in the presence of arbitrary heteroskedasticity, but at a cost of possibly poor finite sample performance. If heteroskedasticity is in fact not present, then standard IV may be preferable[15]. Given that Dynamic model can be specified as follows and it shows that current growth depends on past

$$
\text { Yit }=\mathrm{B} 0+\mathrm{ai}+\mathrm{B} 1 \mathrm{yit}-1+\mathrm{B} 2 \mathrm{x}+\text { uit }
$$

In this equation the following points are taken as instructive assumption, where ai is individual difference or 
unobserved effect. When we run the analysis by using linear or static model, confidently the following limitations have been existing.

1. The explanatory variables in xit are assumed to be endogenous and it may be correlated with the error term.

2. The fixed effects are contained in the error term in equation (1) which consists of the unobserved countryspecific effects "vi" and the observation specific errors "eit". meaning that,

uit $=$ vi + eit

3. The presence of lag dependent variable yit-1 gives rise to autocorrelation.

4. Panel dataset has a short time dimension and a larger country dimension, result to random walk.

The difference GMM can be transformed as;-

$$
\Delta \text { Yit }=+ \text { B1 } \Delta \text { yit }-1+\mathrm{B} 2 \Delta \mathrm{xit}+\Delta \text { uit }
$$

(In general form the transformation is given by:

$\Delta$ yit $=$ B1 $\Delta$ yit $-1+\Delta^{\prime} \mathrm{x}$ it $\beta 2+\Delta$ uit. $)$

By transforming the regressors by first differencing the fixed country-specific effect is removed, because it does not vary with time. From equation (2) we get

$$
\Delta \text { uit }=\Delta \mathrm{vi}+\Delta \text { eit or uit }-\mathrm{ui}, \mathrm{t}-1=(\mathrm{vi}-\mathrm{vi})+(\text { eit }-\mathrm{ei}, \mathrm{t}-1)=\text { eit }- \text { eit }-1 .
$$

. In general, dynamic models are more efficient than static models to resolve problems such as omitted variable, collinearity among explanatory variables, autocorrelation, heteroskedasticity, and endogeneity and measurement errors. Dynamic panel data methods are appropriate enough for panels arrangement attributed with a small $\mathrm{T}$ and large $\mathrm{N}$, otherwise another model may be preferable[16]. Here the researcher employed system GMM estimation over difference GMM because of that:

$\checkmark \quad$ if the dependant variable close to bring random walk or the instrument close to unity difference GMM is inefficient and bias estimator,

$\checkmark$ When number of " $\mathrm{T}$ " less than $\mathrm{N}$ random walk and it will be bias in this case system GMM is more efficient than difference GMM.

$\checkmark \quad$ Also, Roodman (2006) stated that system GMM estimation is efficient and robust to hetroscadcticty and autocorrelation than Difference GMM estimation. Because system GMM use control variables as instrument.

Mathematically the model can be written as: $-\mathrm{hc}=\mathrm{f}(\mathrm{gov}, \mathrm{nrs}, \mathrm{CONVA})$ hcit $=$ bO + b1hcit $-1+$ b2xit + uit

Where; hc= human capita development, gov= governance indicator (government effectiveness, control of corruption, rule of law, voice and accountability, regulatory quality and Political Stability \&Absence of Violence), $\mathrm{HI}=$ human capital (education and health), CONVA =other control variables such as labor participation rate and foreign direct investment. Econometrics estimation of dynamic panel System GMM model can be estimating as follows.

\section{RESULT AND DISCUSSION}

To analysis the result of this study, mutually descriptive and inferential methods of analysis have been used. For example, under descriptive techniques of analysis; mean, standard deviation, maximum, and minimum values are going to be employed while in inferential statistics dynamic panel system GMM method of data analysis has been used through satisfied the basic requirements of the model like the number of instrument and its validity, autocorrelation, and heteroskedasticity.

Table 4.1 Descriptive summary statistics that show the average value of variables include in the study that contain the data from 2005-2018 of sub Saharan African countries.

\begin{tabular}{lllll}
\multicolumn{1}{c}{ Variables } & Mean & Sd & Min & Max \\
\hline Human capital & 111.4 & 489.7 & 1.117 & 3,298 \\
Resource endowment & 12.90 & 11.69 & 0.00118 & 59.60 \\
Labor participation rate & 69.07 & 11.94 & 42.38 & 90.34 \\
Foreign direct investment & 7.801 & 1.627 & -7.397 & 9.885 \\
Control of corruption & 32.52 & 21.95 & 0.948 & 83.90 \\
Government effectiveness & 28.39 & 20.29 & 0.948 & 81.73 \\
Political stability and absence of violence & 33.00 & 22.36 & 0.476 & 93.75 \\
Regularity quality & 31.36 & 18.73 & 0.490 & 83.65 \\
Rule of law & 31.82 & 20.25 & 0.474 & 83.25 \\
Voice and accountability & 34.89 & 19.46 & 2.463 & 79.80 \\
\hline
\end{tabular}

Source: computed from 2019 World Bank and Penn world data source

Results show that on average human capital development which indicates the average schooling and returns to education in Sub-Saharan African countries grow at 111.4 percent in the last 14 later years with a minimum value of 1.117 percent and maximum value of 32. 89. But the deviation of human capital development from the mean across SSA countries is 489 percent. This implies that diversion of human capital across SSA countries. 
Another decisive variable included in this investigation is foreign direct investment net inflows in the percentage of GDP (FDI). The result demonstrates that on average foreign direct investment inflow was 7.8 percent for the last 14 years with a maximum value of 9.88 percent and a minimum value of -7.3 percent in SSA countries. Its standard deviations were 1.62. It directs that the rate at which the percentage of FDI inflow between SSA countries was varied by 1.62 percent .i.e there is a wide difference in FDI inflows between countries. The average endowed resource in the percentage of GDP in Sub Saharan African countries accounted for 12.9 percent and its deviation from the mean is 11.69 percent in the last 14 consecutive years. The average labor participation (LPR) in SSA countries accounted for around 69.07percent and its deviation from the mean is 11.9 percent in the last fourteen years. The average perception of governance indicators like control of corruption, government effectiveness, political stability and regularity quality rule of law and voice and accountability account for 32.52 percent, 28.39 percent, 33.00 percent, 31.36 percent, 31.82 percent and34.89 percent, respective. The respective deviations of the above governance indicator variable from the mean account for 21.95 , percent 20.29 percent, 22.36 percent, 18.73 percent, 20.25 percent, and 19.46 percent.

Table 4.2 Econometrics result of dynamic panel two step system GMM model results

\section{VARIA BLES}

Lag of human capital

Resource endowment

abor participation rate

Foreign direct investment

Control of corruption

Government effectiveness

Political stability and no violence

Regularity quality

Rule of law

Voice and accountability

Constant

Observations

Number of years

ar1p

$\operatorname{ar} 2 \mathrm{p}$

Hansenp

Sarganp

Number of groups

Number of IV

\section{Coefficient}

$0.192 * *$

$(0.077)$

$-10.442 *$

(5.732)

$-14.178 * *$

(2.310)

$-0.000^{*}$

$(0.000)$

$-10.223$

(17.851)

16.479

(17.550)

$-2.155$

(3.414)

$-13.156^{*}$

(6.339)

$-29.906 * *$

(13.311)

$46.160 * * *$

(11.271)

$1,125.118^{* * *}$

$(257.351)$

489

14

0.0177

0.101

0.353

0.845

14

12

Note; - Standard errors in parentheses $* * * \mathrm{p}<0.01, * * \mathrm{p}<0.05, * \mathrm{p}<0$ indicts the level of significances of variables at different level of significance such as 1 perecent 5 percent and 10 percent, respectively.

The results of this model have to be satisfied the validity of instrument, absence of autocorrelation, hetroskedasticity problem and the number of instrument should be less than number of group [16]. Hence, Results of the above dynamic panel two-step System GMM model definitely fulfilled the regular precondition. Lag of human capital index. i.e it represented by the lag of the average year of schooling and returns of education has a positive and significant effect on human capital development at a 5 percent level of significant. This implies that when the previous average year of schooling and returns to education increase by one year, the current average year of schooling increases by 0.192 units. Result redirects that, the base year human capital level has a positive and a significant effect to escalate the returns to education and their average year of schooling in the case of SubSaharan African countries. In line with result of [17] results of this study revealed that resource endowment has a negative and a significant effect on human capital development in sub Saharan African courtiers. Resource endowment percentage of GDP is statistically significant at 10 percent level of significance. An increase resource endowment in percentage of GDP results to a decrease in human capital by 10.44 units. This because of that Sub- 
Saharan African countries are more endowed with natural resource but still they are underdeveloped. Resource endowed countries have less attention on empowering degree of human capital development rather only their capacity depend on their endowed resource. Rather resource endowment become course for conflict and instability, in turns, this led to deteriorate economic growth and this situation known as resource curse. Simply, this resource endowment is amplifying source of less skilled job opportunity over than increase resource endowment.

Also, labor participation rate (LPR) is statistically significant at a 1 percent level of significance but it is negatively related to the human capital indicator which is average year of schooling and returns to education. Increase labors working hours increase by one hour, the individuals' average year of schooling and education returns decrease by 14.179 years. The result indicates as the working hour of the labor force increase, the capacity to boosting adequate human capital accumulation can be harmfully distress. Basically, high participation of young labor in the economy becomes a sensitive cause for decrease future human capital accumulation in sub-Saharan African countries.

Despite the results of [11] the results of this study direct that rule of law and regularity quality are statistically significant at 5 percent and 10 percent level of significance, and negatively affect human capital development in sub-Saharan African countries. Also, voice and accountability have a positive and statistically significant at 1percen level of significance. This has a positive effect on human capital development. While other governance indicators such as control of corruption and political stabilities are statically insignificant. Good governance can give out as an entry point to raising institutional performance in the delivery of education services. Crucial to high performance are standards, information, incentives, and accountability. But governance institution in sub-Saharan African countries is attributed by defective in implement rule and regulation in line with principles and procurers of rule of law. Quality of governance indicator can be effective either to escalate economic growth or human capital development when the levels of institutions are effective else it become one cause of decreasing level of human capital development.

\section{CONCLUSION}

Human capital is a wide thought that inclusive enhancing individual capacity through attaining school; provide incentive, training, and uplift their entrepreneurial ability. As different empirical results authenticated, in any developing countries resource-abundant and good governance are considered as a grace of wheel for human capital. Nevertheless, this study verified that resource richness is deteriorating factor of human capital. Unlike the constructive effect of natural resources to hasten infrastructure it confines human capital accumulation. Resource richness rise society to be reluctant to tutor through increase their engagement in unskilled work and it limiting the perception of them to look for new opportunity. God governance indicators are indispensable to raise human capital for a country which has effective institution while for countries has defective institution negatively affect human capital. Hence, results authenticated that good governance indicators are grace of the wheel for human capital development. Good governance institution helps to increase human capital by increase investments and employment opportunities. Therefore, responsible bodies in sub-Saharan African countries should be formulating good governance principles, and resource merit institution in the favor of human capital development.

\section{Declaration,}

Ferede Mengistie: Conceived and designed the data; Performed the data; Analyzed and interpreted the data.

\section{Reference}

[1] A. Keser and Y. Gökmen, "Governance and Human Development: The Impacts of Governance Indicators on Human Development,” J. Public Adm. Gov., vol. 8, no. 1, p. 26, 2018, doi: 10.5296/jpag.v8i1.12336.

[2] H. Sun, W. S. Y. Geng, And, and Y. Kong, "Natural resource dependence, public education investment, and human capital accumulation," Pet. Sci., vol. 0, no. 2016, 2018, doi: 10.1007/s12182-018-0235-0.

[3] H. Lenihan, H. McGuirk, and K. R. Murphy, "Driving innovation: Public policy and human capital," Res. Policy, vol. 48, no. 9, p. 103791, 2019, doi: 10.1016/j.respol.2019.04.015.

[4] Mohammed Shuaibu, T. Oladayo, and Popoola, "OeconomiA Determinants of Human Capital Development in Africa : A Panel Data Analysis," vol. 7, no. 4, 2016.

[5] H. Rjoub et al., "Implications of governance, natural resources, and security threats on economic development: Evidence from sub-saharan africa," Int. J. Environ. Res. Public Health, vol. 18, no. 12, 2021, doi: $10.3390 /$ ijerph18126236.

[6] C. Huang, "North American Journal of Economics and Finance Is corruption bad for economic growth ? Evidence from Asia-Pacific countries," North Am. J. Econ. Financ., vol. 35, no. 100, pp. 247-256, 2016, doi: 10.1016/j.najef.2015.10.013.

[7] K. Ogundari and T. Awokuse, "Human capital contribution to economic growth in Sub-Saharan Africa: Does health status matter more than education?," Econ. Anal. Policy, vol. 58, no. February, pp. 131-140, 2018, doi: 10.1016/j.eap.2018.02.001. 
[8] E. M. Caucutt and L. Lochner, "Early and late human capital investments, borrowing constraints, and the family," J. Polit. Econ., vol. 128, no. 3, pp. 1065-1147, 2020, doi: 10.1086/704759.

[9] J. Liu, J. Tang, B. Zhou, and Z. Liang, "The effect of governance quality on economic growth: Based on China's provincial panel data," Economies, vol. 6, no. 4, pp. 1-23, 2018, doi: 10.3390/economies6040056.

[10] I. D. Raheem, K. O. Isah, and A. A. Adedeji, "Inclusive growth, human capital development and natural resource rent in SSA," Econ. Chang. Restruct., vol. 51, no. 1, pp. 29-48, 2018, doi: 10.1007/s10644-0169193-y.

[11] Z. Ahmad and A. Saleem, "Impact of governance on human development," Pakistan J. Commer. Soc. Sci., vol. 8, no. 3, pp. 612-628, 2014.

[12] Y. Herizal, S. L. Z. Ridho, \&, and R. Anggraini, "GOVERNMENT EXPENDITURE AND CORRUPTION: AN INDONESIA EXPERIENCE," Public Sect. Accounting, Financ. Cris. Austerity, Birmingham, 1 - 4 Sept. 2013., pp. 1-16, 2013.

[13] C. J. Huang, "Is corruption bad for economic growth? Evidence from Asia-Pacific countries," North Am. J. Econ. Financ., vol. 35, no. 100, pp. 247-256, 2016, doi: 10.1016/j.najef.2015.10.013.

[14] R. Mosquera, "A Blessing or a Curse? The Long-Term Effect of Resource Booms on Human Capital and Living Conditions,” SSRN Electron. J., no. March, 2019, doi: 10.2139/ssrn.3364717.

[15] GutierrezRobert and E. Rachid, "Using a Dynamic Panel Estimator to Model Change in Panel Data," pp. $1-10,2017$.

[16] C. F. Baum, "Instrumental variables and panel data methods in economics and finance," no. February, 2009.

[17] S. Oniyangi, "The Effects of Natural Resources on Gender Inequality: An Explanation for the Resource Curse? Submitted to the Department of Economics of Amherst College in partial," 2013. 